\section{Reconocimiento a Ingeborg Prenzel Leupold}

\section{Tribute to Ingeborg Prenzel Leupold}

\section{Sr. Editor:}

Al emprender esta tarea, que busca ser un homenaje, recuerdos y sentimientos se encuentran con realidades que permiten bosquejar la imagen de uno de los personajes más interesantes y entrañables de nuestra Pediatría, aunque su fructífero desempeño no lo llevó a cabo desde su condición de "Pediatra" sino desde el de su disciplina preferida, la Microbiología Clínica, íntima e inseparablemente ligada a la actividad pediátrica clínica.

La figura y obra de la Dra. Ingeborg Prenzel está inserta en la cohorte olvidada por las generaciones que siguieron a la de ella, no obstante constituir una pieza crucial de la Historia de la Pediatría moderna chilena, que lo es en la medida en que para muchos es difícil pensar que, antes de la actual "modernidad", existió una etapa de lucha contra la escasez de medios y oscuridad de conceptos cuyo vencimiento requirió no sólo mucho esfuerzo, sino creatividad y firmeza de convicciones para crear la fructífera modernidad de entonces.

Ingeborg Silvia Prenzel Leupold nació en Concepción el 16 de marzo de 1930, donde hizo sus estudios desde primaria hasta completar los de Medicina, rindiendo exámenes para graduarse de Médico en la Universidad de Chile en Santiago, el año 1956.

De allí regresó a Concepción, donde fue residente del Hospital Regional en Pediatría en las mañanas y en Microbiología en las tardes. Durante este período hizo una pasada por el Hospital Lucio Córdoba para perfeccionarse en Enfermedades Infecciosas.

Posteriormente, la Universidad de Concepción le otorgó una beca en Pediatría y Virología en el Hospital Universitario de Hamburgo, Alemania, en el período 1958-60 para cumplir el programa oficial en ambas disciplinas, lo que explica su poco común cercanía, como microbióloga, a la clínica pediátrica.

A su vuelta en Chile, volvió al Hospital Regional de Concepción donde se desempeñó, nuevamente, como Pediatra clínico y Microbiólogo, en medias jornadas.

Casó con Francisco Iduya Fernández De la Peña en 1966, por lo que debió migrar a Santiago, incorporándose al Hospital Sótero del Río como Pediatra y Microbióloga, correspondiéndole llevar a cabo la reorganización del Laboratorio de Microbiología de dicho hospital.

En el año 1969 ganó el concurso para llenar su cargo de Microbióloga en el Hospital Roberto del Río, donde permanecería trabajando a jornada completa hasta 2006.

Ingeborg ("Inge" para nosotros, sus compañeros de trabajo) se incorporó al Laboratorio de Microbiología del Hospital Roberto del Río en 1969.

Su nombre y su aspecto, fieles expresiones de su inte- rior, chileno de corazón pero impregnado de las mejores virtudes de su cultura europea, se completan con su sonrisa fácil y su siempre bien dispuesto humor para emprender con entusiasmo y leal espíritu de colaboración, las empresas que se le propusieron para aprovechar la solidez de sus conocimientos y la confiabilidad de su rigurosa, no obstante, amable personalidad.

Nuestro trabajo asociado $-\mathrm{y}$ nuestra amistad, como en el caso de muchos- se iniciaron a raíz de un desafío surgido, prácticamente por acción del azar. A pesar de que Hattie Alexander había publicado sus notables experiencias con Haemophilus influenzae a comienzos de la década de los 40 y Sarah Sell destacaría su importancia en 1970, la noción de su incidencia en la morbilidad de los niños de América Latina era casi nula. En la búsqueda de un modelo de "sepsis"-término inespecífico y común en niños presuntamente infectados sin que se lograra identificar el agente causal- dimos con las infecciones por esta bacteria como protagonista de un modelo de lo que se llamaría "infección invasora" - más cercano y preciso, ahora con la denominación de "septicemia"-pero, ¿cómo estudiarla? La difusión del conocimiento y los recursos de laboratorio fueron, durante más de 40 largos años, lenta e incompleta y en la literatura nacional se menciona este agente infeccioso en niños sólo circunstancialmente -en autopsias de niños con meningitis- en 1947.

Frente la imposibilidad de obtener los factores de crecimiento - X y V-para su cultivo e identificación, que la literatura mencionaba como indispensables, ella resolvió esta fase del problema mostrándonos cómo el fenómeno de "satelitismo", utilizando una cepa de Staphylococcus aureus (como se llamó al $S$. coagulasa + ) inoculada en el medio de que disponíamos, nos permitió el primer gran paso para iniciar lo que resultaría una revelación y un enorme progreso en el estudio de este agente de meningitis del niño menor y sus patologías asociadas, acercándonos con nuestro diagnóstico no sólo a la identificación en pacientes con meningitis instalada -como describían los textos de entonces- hasta la descripción del niño "en riesgo de bacteriemia" -y meningitis bacteriana- lo que significó un indiscutible avance, nunca bien ponderado, en nuestra práctica clínica.

Ajena a rivalidades y deseos de aparecer en primera línea, dan cuenta de su contribución los numerosos artículos publicados sobre estas materias y otras en las que se contó con su colaboración, junto con otros distinguidos especialistas en Microbiología nacionales y extranjeros, en la Revista Pediatría (Santiago de Chile), Boletín del Hospital Infantil de México, Revista Médica de Chile, Journal of Infectious Diseases, Clinical Infectious Diseases, The Lancet, etc., entre los años 1975-1990, en los que su participación era críticamente importante para seguir contribuyendo, con su dedicado y confiable trabajo, a los estudios que siguieron en el campo del desarrollo y ensayo 
de vacunas contra este agente infeccioso y otros, como los ensayos de la vacuna Ty $21 \mathrm{a}$, en los años que siguieron.

A raíz del brote epidémico de meningococcias durante los años 1978-79 en Santiago, el Hospital Roberto del Río fue designado por el Ministerio de Salud como Centro de Referencia de casos en niños de la Región Metropolitana, en gran parte debido a que contaba con la Bacteriología de la Dra. Prenzel y su equipo de trabajo: sólo uno de los casos recibidos por el hospital no fue confirmado bacteriológicamente, debido al sobrecalentamiento de un horno de Pasteur, en el área a cargo de la Residencia Pediátrica del Hospital. Sin la necesidad de normas escritas -a las que ella contribuyó a elaborar como instructivo del Ministerio para la detección y manejo de pacientes y muestras de meningococcias a lo largo del país- bastó la cercanía habitual entre su trabajo y el de los clínicos a cargo para que este alto rendimiento tuviese lugar.

Había pocas inquietudes de los clínicos que ella no supiera acoger, con su enorme generosidad y esfuerzo. A fines los años 70, ante requerimiento de contar con cultivo y diagnóstico micológicos, y a instancias de sus colegas del área clínica, se inscribió en el Curso de Micología que dictaba el Profesor Carlos Negroni, durante sus visitas desde Argentina a Valdivia, curso dictado en la Facultad de Medicina de la Universidad Austral de Chile: ello dotó a nuestro laboratorio de este inestimable recurso.

Es un hecho cierto, aunque frecuentemente ignorado, que la información rutinaria de laboratorios (así como el contenido de historias clínicas) sin la elaboración de procedimientos $-\mathrm{o}$ registros- ad hoc según un objetivo explícito, no proporcionan consistencia a los estudios que se basan en ellos. El trabajo de la Dra. Prenzel según nos consta a todos los que nos propusimos un objetivo con su colaboración, cumplía los estándares exigibles para usarlos en investigación clínica. Da cuenta de lo anterior, no sólo el porcentaje de verdaderos positivos -o negativos- de sus procedimientos, sino la rigurosidad en todo cuanto hacía y, sobre todo, la abierta disposición a aceptar objeciones, siempre que éstas pudiesen ser discutidas.

Notable era, en una época de una considerable desproporción entre las inquietudes y los recursos para satisfacerlas, la entrega regular de la sensibilidad de las diferentes bacterias a los antibióticos para el mejor uso de éstos por parte de los clínicos del hospital, materia que se convertiría con el devenir de los años, en una disciplina central en el trabajo clínico del siglo XXI.

La implementación del diagnóstico de escabiosis en el laboratorio del hospital, en su más alto nivel de sensibilidad y especificidad, fue otro valioso aporte de su dedicación y pericia microbiológica, todo esto sin exigir recursos extraordinarios y costosos que habría sido imposible conseguir dentro de un presupuesto asignado que no contemplaba la labor académica y de investigación que, de hecho, realizaba la Dra. Prenzel.

Tal vez el rasgo que mejor la define, además de lo ya destacado en términos de seriedad y confiabilidad técnicas, ha sido su gran generosidad para entregar sus conocimientos a sus colaboradores más próximos y a cuanta persona se interesara, ya fuese médico "asistencial", académico o personal en formación, que se acercara a su ordenado y limpio laboratorio, en el que podía recorrer, en busca de datos para sus inquietudes, sus libros de registro ordenados y en los que se encontraba -mezclada con la letra de sus subalternos y colaboradores- su inconfundible caligrafía, signo de que no sólo dirigía sino que se involucraba trabajando, aún siendo el Jefe responsable, mezclada con lo que era su equipo, también recordado por quienes tuvieron la suerte de trabajar en el hospital durante los años en que ella lo hizo.

Su espíritu equilibrado, ajeno a la exposición pública o demostraciones de ilustración profesional, así como la noción de que su figura humana y profesional son argumentos suficientes para permitir reconocer sus orígenes y han sido parte de su vida de mujer chilena a la vez que determinante de ser ajena a la búsqueda de reconocimientos y honores, además de constituirse ésta, su actitud natural, en beneficio de un balanceado mundo en que el trabajo profesional y su vida privada han tenido un sitio preciso y distinto en sus afectos.

Así, al cabo de una larga vida de éxitos profesionales útiles a la sociedad en que le tocó vivir y prodigar abundantemente su bondades humanas, terminó su trabajo y dejó su querido laboratorio, sin grado académico alguno ni expresión de reconocimiento público suficiente, no obstante la expresión de pérdida que quienes trabajamos con ella percibimos a raíz de su alejamiento.

Por todo lo anterior quien subscribe, interpretando el deseo de quienes han conocido a "Inge" Prenzel, quiere rendir un homenaje de reconocimiento, admiración y gratitud por quien fue una silenciosa trabajadora, maestra generosa y leal amiga, compañera de labores en momentos importantes de la Historia de la Pediatría e Infectología chilenas, como un testimonio para el conocimiento de las actuales y futuras generaciones de médicos.

\author{
Patricio Herrera \\ Ex-Presidente \\ Sociedad Chilena de Infectología
}

